\title{
SPIES optical biopsies in laryngeal papillomatosis. The 4 waves sign
}

\author{
VIOREL ZAINEA ${ }^{1,2}$, IRINA GABRIELA IONITA ${ }^{1,2}$, SILVIU PITURU ${ }^{1}$, CATALINA PIETROSANU ${ }^{1,2 *}$, \\ ANDREEA RUSESC ${ }^{1}$, CRISTIAN DRAGOS STEFANESCU ${ }^{1,3}$, FLORENTINA GHERGHICEANU ${ }^{1}$, \\ FLORIN ANGHELINA ${ }^{4,5}$, DRAGOS PALADE, ${ }^{6,7}$, OANA ELENA AMZA ${ }^{1}$, RAZVAN HAINAROSIE ${ }^{1,2}$ \\ 1"Carol Davila" University of Medicine and Pharmacy, $8^{\text {th }}$ Eroii Sanitari Boulevard, Bucharest, Romania \\ 2"Prof. Dr. D. Hociota" Institute of Phonoaudiology and Functional ENT Surgery, $21^{\text {st }}$ Mihail Cioranu \\ Street, Bucharest, Romania \\ ${ }^{3}$ National Aviation and Space Medicine Institute, $88^{\text {th }}$ Mircea Vulcanescu Street, Bucharest, Romania \\ ${ }^{4}$ University of Medicine and Pharmacy of Craiova, $2^{\text {nd }}$ Petru Rares Street, Craiova, Romania \\ ${ }^{5}$ Emergency County Hospital Craiova, $1^{\text {st }}$ Tabaci Street, Craiova, Romania \\ 6"Grigore T. Popa" University of Medicine and Pharmacy, $16^{\text {th }}$ Universitatii Street, Iasi, Romania \\ 7“'Saint Spiridon" Emergency University Hospital, $1^{\text {st }}$ Independentei Boulevard, Iasi, Romania
}

\begin{abstract}
Laryngeal papillomatosis represents a challenging disease for the ENT surgeon. It has a recurrent pattern, with lesions that tend to be more and more extensive and affect the quality of life of the patient. Due to it's viral etiology, multiple medical therapies have been attempted for these patients. Their results are still somewhat controversial, taking into account the local and systemic side effects. Diabetes mellitus (DM) patients are considered to be relatively immunocompromised and the laryngeal papillomatosis is more severe.

The lesions occur at an epithelial level. The earlier the diagnosis, the better the outcome of the patient. The advancements made in the field of medical technologies made possible ample surgical interventions that maintain the natural airway. Out of these, the most used today is the CO2 LASER, with good results when correctly managed.

The purpose of this paper is to present the use of an endoscopic method of examination, that uses SPIES filters, for a more accurate diagnosis of the epithelial lesions, which allows a better evaluation and more thorough follow-up of our patients. We believe attention should be paid to this topic due to the surgical, epidemiological and biological reasons.
\end{abstract}

Keywords Laryngeal papillomatosis, CO2 LASER, SPIES, diabetes.

To cite this article: ZAINEA V, IONITA IG, PITURU S, PIETROSANU C, RUSESCU A, STEFANESCU CD, GHERGHICEANU F, ANGHELINA F, PALADE D, AMZA OE, HAINAROSIE R. SPIES optical biopsies in laryngeal papillomatosis. The 4 waves sign. Rom Biotechnol Lett. 2021; 26(1): 2318-2322. DOI: 10.25083/rb1/26.1/2318.2322

Q *Corresponding author: CĂTĂLINA PIETROȘANU, "Prof. Dr. D. Hociotă" Institute of Phonoaudiology and Functional ENT Surgery, $21^{\text {st }}$ Mihail Cioranu Street, Bucharest, Romania

E-mail: catapietrosanu@gmail.com Phone: +40723627405 


\section{Introduction}

Laryngeal papillomatosis is a recurrent condition, caused by the infection with the human papilloma virus. This condition has no curative treatment, however multiple types of surgical and medical treatments are available and aim for local control of the disease, despite the fact that in multiple occasions the patients will undergo several procedures (T.Q. GALLAGHER et al, 2009 [1]). That is due to the high tendency for recurrence of the disease. Systemic medication can be considered, with the use of substances such as acyclovir, interferon and isoretinoin being researched on various occasions. However, the systemic toxic reactions must be considered (P. GOON et al, 2008 [2], I. BIELECKI et al, 2009 [3]).

The disease can be contacted by sexual intercourse or at birth, when a mother with genital papillomatosis gives birth naturally. Although the most common cases of infection involve genital papillomatosis, the laryngeal location of the disease can be quite serious due to the invalidating character of the disease and the tendency to recurrence, especially for the cases of congenital papillomatosis. The most often involved subtypes are HPV 6 and HPV 11, and they may also associate malignant turnover. The incidence in adults is 1.8 in 100.000 people, but in can go as high as 4.3 in children. Diabetes mellitus (DM) patients are considered to be relatively immunocompromised and the laryngeal papillomatosis has a more severe evolution. (C.L. LEE et al, 2013 [4]).

Various surgical procedures have been attempted for these patients. If at first, the tracheotomy was the only way to ensure the air flow, more elaborate procedures attempt now to maintain the natural airway free and ensure a better quality of life for patients with laryngeal papillomatosis The development of new cutting technologies, such as the CO2 LASER, opened new perspectives in the treatment of our patients, with outstanding results and a better compliance (F.G. DIKKERS, 2006 [5]).

Numerous adjuvant therapies have been considered. The intralesional injection of substances was naturally considered, with the hope of superior local control of the disease. Van Cutsem first reported success using Cidofovir in 1995, for a patient with hypopharyngeal and esophageal papillomatosis (E. CUTSEM et al, 1995 [6]). However, the initial enthusiasm was lowered by the associated side effects that appeared in time, such as dysplasia of the mucosa after injection (J.A. SAJAN et al 2010 [7]) or even the development of squamous cell carcinoma (D.G. LOTT et al, 2009 [8]).

Although we have studies that do not link the local administration of Cidofovir with dysplastic degeneration (A.J. DOONE et al 2008 [9]), other research suggest an important risk of malignant degeneration associated with the procedure, ranging from $3-5 \%$ to as high as $23 \%$
(D.W. KIMBERLIN et al, 2000 [10], H.T. GUPTA et al, 2010 [11]).

Today local therapies are still researched, with the study of efficiency and side effects being one of the prime directives (B.J. CHUNG et al, 2006 [12], V. ARDELEANU et al, 2015 [13]). However, due to the development of diagnosis and surgical technologies, the surgical interventions aim for local control of the disease with minimum side effects. The use of CO2 LASER for a complete removal of the papillomatosis lesions has so far associated a good outcome. Of course, the less extensive the lesions, the easier it is to achieve a functional larynx, with lasting results and minimal complications. That is why a great emphasis is placed on aggressive follow-up and early diagnosis of any recurrence (C. MEHEDINTU et al [14]).

The aim of this paper is to identify the main lesions induced by the human papilloma virus (HPV) at the level of the epithelial layer of the vocal folds. We wish to present specific lesions induced by HPV at an endoscopic magnified scale, by means of filtered light from the software provided by a digital special camera. This technology is called SPIES.

The objective is to find characteristic aspects concerning the cycle of lesions induced by the human papilloma virus.

\section{Materials and Methods}

The study was an observational endoscopic study focused on the endoscopic magnified landscape and analyzed with SPIES digital technology. The area investigated is represented by the endolarynx. The study was performed between 2015 and 2016 and included 24 clinical cases with laryngeal HPV induced lesions. In our group 9 women and 15 men were included, age ranging from 21 to 53 years old. Out of these 24 patients, 14 had already undergone previous surgical interventions for laryngeal papilomatosis. We did not include cases with congenital lesions. We also consider important mentioning that 8 patients presented with significant comorbidities, including high blood pressure and ischemic cardiac disease, and 5 patients were known with diabetes, 2 of which required the use of insulin. Patients with malignant degeneration of the lesions were not included in the study.

The method: the vocal folds were analyzed during microlaryngoscopy under general anesthesia using the rigid laryngeal 0 degree Hopkins endoscope attached to the full HD endoscopy camera with SPIES software technology (by Karl Storz). The software filters that we applied on the lesion were:

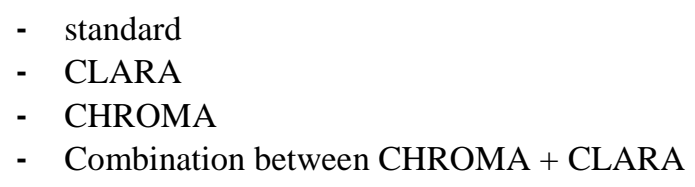


- SPECTRA A

- SPECTRA B

The SPIES filters is the acronym from Storz Professional Image Enhancement Filters. Applied on the full HD endoscopic image, the software filters allow the surgeon to better visualize some morphologic details of the lesion and the vascular superficial design.

CLARA filter will increase the luminosity of the image, the surgeon is able to better observe even the most darken places of the endoscopic examination.

CHROMA filter will increase the contrast of the endoscopic image and especially of the highlighted structures.

SPECTRA A filter will remove from the endoscopic image the red component, the obtained image is similar with the one when applying the Narrow Band Imaging filter. The epithelium that reflects light is better visualized and the areas that do not reflect light, as blood vessels and papillary tumors, are highlighted.

SPECTRA B filter is obtained by applying on the image filtered with SPECTRA A 15\% more red color, which will lead to a better visualization of the darkened areas of the endoscopic field.

With these filters we considered very important to analyze the following structures:

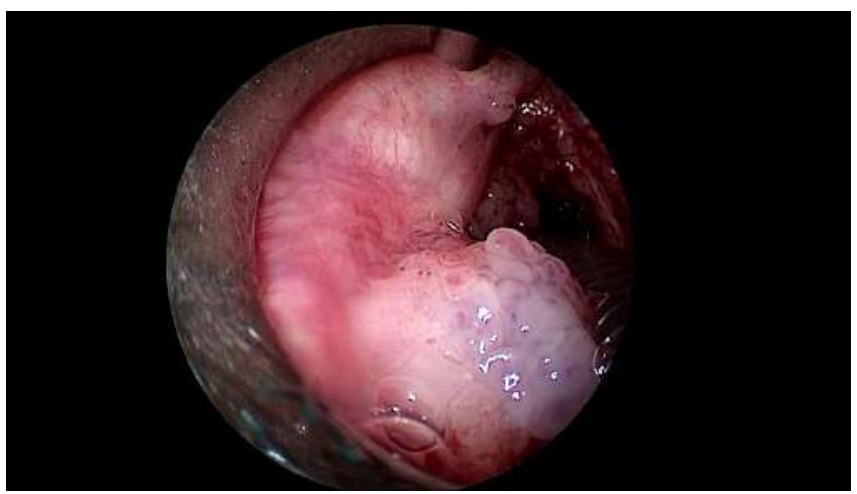

Figure 1. Assessment of a papilloma using white light endoscopy.

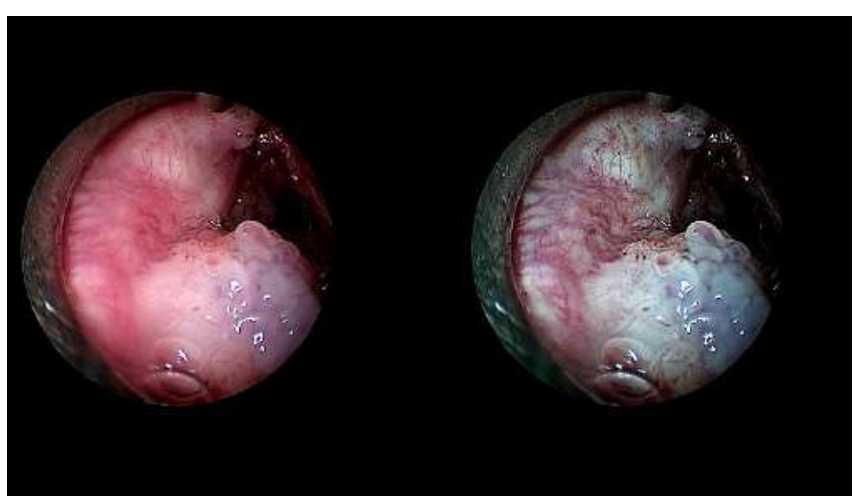

Figure 2. SPECTRA B analysis of the same papilloma, with a superior definition of the safety margins. a. the lesion;

b. the surrounding area;

c. the border of the healthy tissue (which we can call a "safe margin").

With this method we could point out the "fragility" of the lesion, the surrounding tissue and the resection margins. We wish to resect the affected epithelium above the basal membrane and try to define the limit (border) between pathologic and healthy tissue.

\section{Results}

We were able to identify the " 4 waves sign" during repeated examinations of the vocal fold with the epithelial layer affected by HPV. The meaning: we could identify at a magnified scale the cycle of changes of the HPV epithelial layer interface, using an endoscopic filtered and magnified scale. This is important for the surgical intervention, a 3 layers resection until healthy epithelial "safe margins" being achieved.

The endoscopic SPIES assessment of laryngeal papillomatosis has surgical implications.

The most important is that using the SPECTRA B and CLARA+CHROMA filter we were able to better define the epithelial halo surrounding the papilloma (Fig. 1, Fig. 2 and Fig. 3).

The results consisted in the "4 waves sign", which contains 4 areas with:

a. pink colour;

b. red colour;

c. "toof" papilloma;

d. a white and grey area with many cells destroyed by the virus. This is the superficial layer with necrotic epithelium and virus cells, which is eliminated. This area is contagious and detachable.

We compared the results obtained using the SPIES filters with the result obtained by histopathological exam.

\section{Discussions}

The endoscopic diagnostic and surgical technologies have advanced greatly in the past 10 years. These advancements are related to the following aspects:

- the ability to display a lesion, it's topography, the resection base, the surroundings and limits.

- the capacity to orient and document the type of resection or excision taking into account the idea of "safety margins" or "maximal safe resection" when certain local anatomical and lesion characteristics imply a less extensive surgical resection.

- the capacity to suggest and presume histologically specific lesions without a direct tissue sample (the so-called endoscopic "optical biopsies").

Few research studies focused on this type of clinical research so far, which is situated somewhere between the 


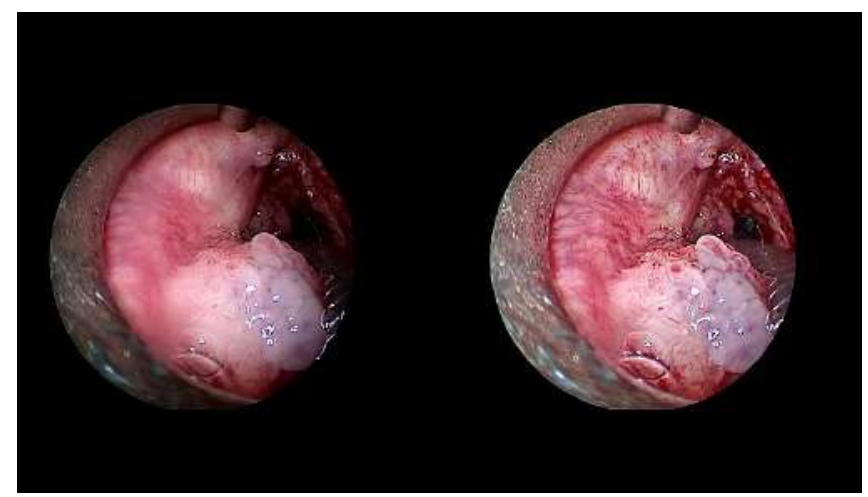

Figure 3. CLARA + CHROMA view of the papilloma, with all 4 areas specific to the disease pattern of spread present.

The SPECTRA A filter in our experience will provide a too dark image of the endoscopic field. Another disadvantage of the SPECTRA A filter is that it amplifies the vascular design and if blood is present in the surgical field, the endoscopic detail is hard to be observed.

CHROMA+ CLARA combination and SPECTRA B are the optimal filters to be used in order to asses the "safe area" surrounding the papilomatous tumor and the obtained endoscopic detail is good even when blood is present in the surgical field.

\section{Conclusions}

The refining of the optical, electronic and digital technologies (videocontact endoscopy, NBI wavelength, SPIES filters) or the laser stimulation of normal biologic properties of the examined tissue offer interesting details, that are useful in the diagnosis and the process of choosing the right type of surgical intervention in real time. The idea we want to promote is that of in vivo and in situ endoscopic study.

Despite small studies present in the literature concerning the use of Storz Professional Image Enhancement System (SPIES), because of the novelty of the technology, the result obtained using that technology seems to be promising, but further studies must be performed.

\section{Acknowledgements}

This research was not supported by any funding source.

Authors have no conflict of interest to declare in relation to the conduct of this research and the development of the manuscript.

All authors have contributed equally to this manuscript. level of macroscopic and histopathological research (direct biopsy with histopathological examination) (L. MAZILU et al, 2013 [15]).

Due to videosurgery, that can be applied at multiple levels (rhinosinusal, laryngeal, esophageal, tracheobronchis, esogastric) (C. POPA et al, 2019 [16]), we have the opportunity to study the epithelial layer and vascular architecture in their natural state, both in vivo and in situ (A.TULIN et al, 2018 [17]).

Using the Storz Professional Image Enhancement System (SPIES) we were able to better define the real extension of the disease. The "safe area" surrounding the papilomatous tumor was better identified.

\section{References}

1. GALLAGHER TQ, DERKAY CS. Pharmacotherapy of recurrent respiratory papillomatosis: an expert opinion. Expert Opin Pharmacother. 2009; 10(4):645655. doi:10.1517/14656560902793530

2. GOON P, SONNEX C, JANI P, STANLEY M, SUDHOFF H. Recurrent respiratory papillomatosis: an overview of current thinking and treatment. Eur Arch Otorhinolaryngol. 2008; 265(2):147-151. doi:10.1007/ s00405-007-0546-z

3. BIELECKI I, MNISZEK J, COFAŁA M. Intralesional injection of cidofovir for recurrent respiratory papillomatosis in children. Int $J$ Pediatr Otorhinolaryngol. 2009; 73(5):681-684. doi:10.1016/j.ijporl.2009.01.002

4. LEE CJ, ALLEN CT, MERATI al. Prevalence of diabetes mellitus and its impact on disease severity in adult recurrent respiratory papillomatosis. Otolaryngol Head Neck Surg. 2013; 149(4):603-607. doi:10.1177/ 0194599813496969

5. DIKKERS FG. Treatment of recurrent respiratory papillomatosis with microsurgery in combination with intralesional cidofovir - a prospective study. Eur Arch Otorhinolaryngol. 2006; 263(5):440-443. doi:10.1007/ s00405-005-1013-3

6. VAN CUTSEM E, SNOECK R, VAN RANST M et al. Successful treatment of a squamous papilloma of the hypopharynx-esophagus by local injections of (S)-1-(3-hydroxy-2-phosphonylmethoxypropyl)cytosine. J Med Virol. 1995; 45(2):230-235. doi:10.1002/jmv. 1890450221

7. SAJAN JA, KERSCHNER JE, MERATI AL, OSIPOV V, SZABO S, BLUMIN JH. Prevalence of dysplasia in juvenile-onset recurrent respiratory papillomatosis. Arch Otolaryngol Head Neck Surg. 2010; 136(1):7-11. doi:10.1001/archoto.2009.179 
8. LOTT DG, KRAKOVITZ PR. Squamous cell carcinoma associated with intralesional injection of cidofovir for recurrent respiratory papillomatosis. Laryngoscope. 2009; 119(3):567-570. doi:10.1002/ lary.20082

9. DONNE AJ, ROTHERA MP, HOMER JJ. Scientific and clinical aspects of the use of cidofovir in recurrent respiratory papillomatosis. Int J Pediatr Otorhinolaryngol. 2008; 72(7):939-944. doi:10.1016/j.ijporl. 2008.04.003

10. KIMBERLIN DW, MALIS DJ. Juvenile onset recurrent respiratory papillomatosis: possibilities for successful antiviral therapy. Antiviral Res. 2000; 45(2):83-93. doi:10.1016/s0166-3542(00)00064-4

11. GUPTA HT, ROBINSON RA, MURRAY RC, KARNELL LH, SMITH RJ, HOFFMAN HT. Degrees of dysplasia and the use of cidofovir in patients with recurrent respiratory papillomatosis. Laryngoscope. 2010; 120(4):698-702. doi:10.1002/lary.20785

12. CHUNG BJ, AKST LM, KOLTAI PJ. 3.5-Year follow-up of intralesional cidofovir protocol for pediatric recurrent respiratory papillomatosis. Int $J$
Pediatr Otorhinolaryngol. 2006; 70(11):1911-1917. doi:10.1016/j.ijporl.2006.06.018

13. ARDELEANU V., FRANCU V.L., GEORGESCU C. Neoangiogenesis Assessment in Esophageal Adenocarcinomas. Indian journal of surgery. 2015; 77(3): S971-S976.

14. MEHEDINTU C., PlOtOGEA M, ANTONOVICI M., TODEA C. The Human Papilloma Virus Infection. DermatoVenerol., 58: 277-286.

15. MAZILU L., SUCEVEANU A.I., TOMESCU D., CIUFU N., BAZ R., SUCEVEANU A.P., PAREPA I.R., TOFOLEAN D.E., VOINEA F. Optimizing the Indication for Breast-Conservative Surgery (BCS) in Patients with Locally-Advanced Breast Cancer. Chirurgia. 2013; 108 (4): 478-481.

16. POPA C., CONSTANTIN C., BADIU D.C., ANDRONACHE L.F. et al. Differential Diagnosis in Esophageal Cancer Review on literature. Rev. de Chim. 2019; 70(1):331-335.

17. TULIN A., ALECU L., POIANA C. et al. Functional radical cervical dissection for differentiated thyroid cancer: the experience of a single center. Journal of Mind and Medical Sciences. 2018; 5(2):278-283. 